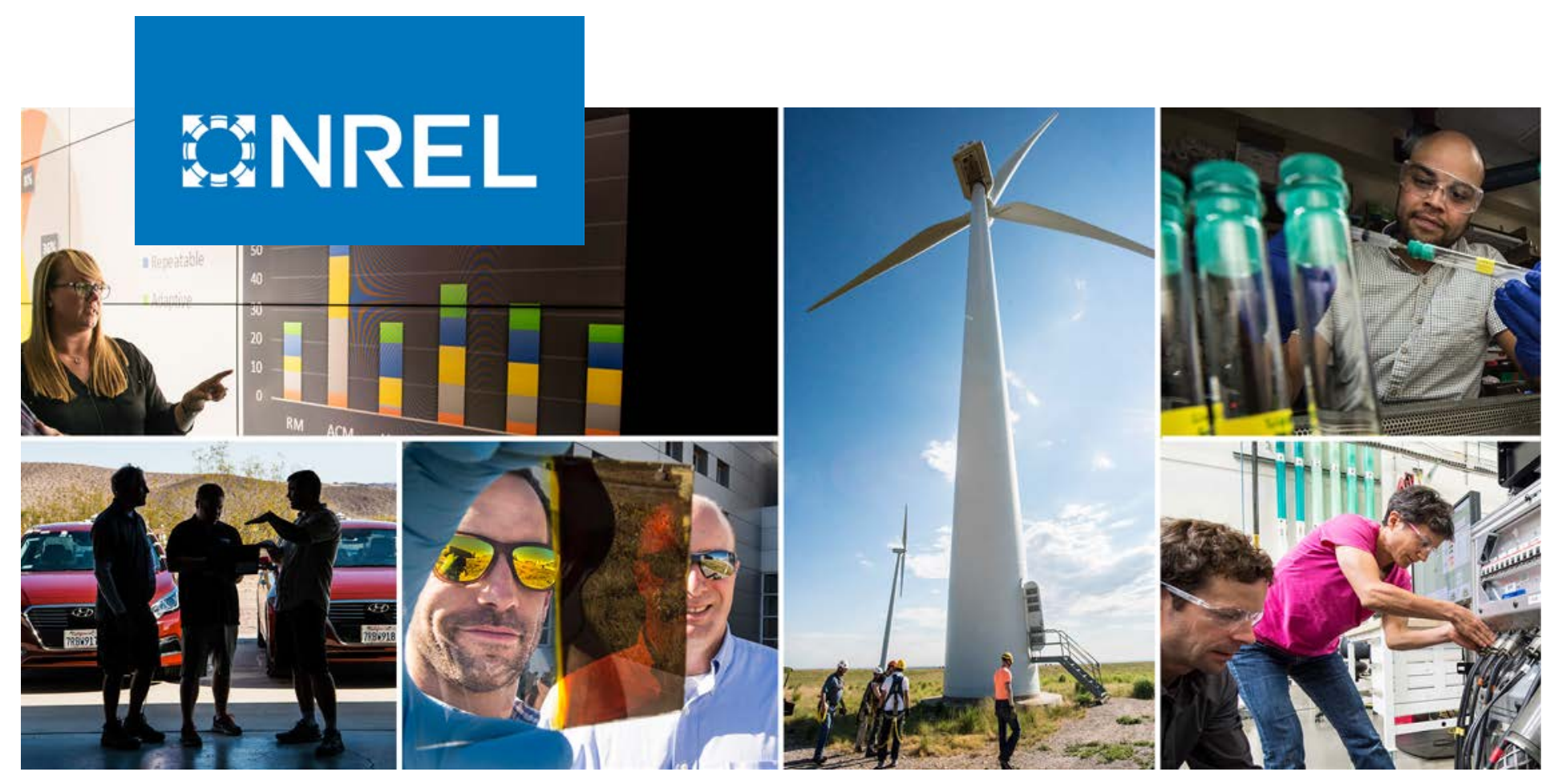

\title{
An Evaluation of the Spectral Irradiance Data from the NSRDB
}

Yu Xie, ${ }^{1}$ Aron Habte,${ }^{1}$ Manajit Sengupta, ${ }^{1}$ and Frank Vignola ${ }^{2}$

1 National Renewable Energy Laboratory

2 University of Oregon

NREL is a national laboratory of the U.S. Department of Energy Office of Energy Efficiency \& Renewable Energy

Operated by the Alliance for Sustainable Energy, LLC

This report is available at no cost from the National Renewable Energy Laboratory (NREL) at www.nrel.gov/publications.
Technical Report

NREL/TP-5D00-80439

September 2021 


\section{GNREL}

\section{An Evaluation of the Spectral Irradiance Data from the NSRDB}

Yu Xie,${ }^{1}$ Aron Habte,${ }^{1}$ Manajit Sengupta, ${ }^{1}$ and Frank Vignola ${ }^{2}$

1 National Renewable Energy Laboratory

2 University of Oregon

\section{Suggested Citation}

Xie, Yu, Aron Habte, Manajit Sengupta, and Frank Vignola. 2021. An Evalutation of the Spectral Irradiance Data from the NSRDB. Golden, CO: National Renewable Energy Laboratory. NREL/TP-5D00-80439. https://www.nrel.gov/docs/fy21osti/80439.pdf.

NREL is a national laboratory of the U.S. Department of Energy Office of Energy Efficiency \& Renewable Energy Operated by the Alliance for Sustainable Energy, LLC

This report is available at no cost from the National Renewable Energy Laboratory (NREL) at www.nrel.gov/publications.

Contract No. DE-AC36-08GO28308
Technical Report

NREL/TP-5D00-80439

September 2021

National Renewable Energy Laboratory 15013 Denver West Parkway Golden, CO 80401

303-275-3000 • www.nrel.gov 


\section{NOTICE}

This work was authored in part by the National Renewable Energy Laboratory, operated by Alliance for Sustainable Energy, LLC, for the U.S. Department of Energy (DOE) under Contract No. DE-AC36-08GO28308. Funding provided the U.S. Department of Energy Office of Energy Efficiency and Renewable Energy Solar Energy Technologies Office. The views expressed herein do not necessarily represent the views of the DOE or the U.S. Government.

This report is available at no cost from the National Renewable Energy Laboratory (NREL) at www.nrel.gov/publications.

U.S. Department of Energy (DOE) reports produced after 1991 and a growing number of pre-1991 documents are available free via www.OSTI.gov.

Cover Photos by Dennis Schroeder: (clockwise, left to right) NREL 51934, NREL 45897, NREL 42160, NREL 45891, NREL 48097, NREL 46526.

NREL prints on paper that contains recycled content. 


\section{List of Acronyms}

DISORT discrete ordinates radiative transfer

FARMS-NIT Fast All-sky Radiation Model for Solar applications with Narrowband Irradiances on Tilted surfaces

NREL

NSRDB

POA

National Renewable Energy Laboratory

PV

National Solar Radiation Database

plane of array

photovoltaic

SMARTS

SRRL

Simple Model of the Atmospheric Radiative Transfer of Sunshine Solar Radiation Research Laboratory 


\section{Executive Summary}

A recent effort by the National Renewable Energy Laboratory (NREL) has led to a new radiative transfer model, the Fast All-sky Radiation Model for Solar applications with Narrowband Irradiances on Tilted surfaces (FARMS-NIT), to efficiently compute spectral irradiances in the plane of array. This model has been implemented in the National Solar Radiation Database to provide the photovoltaic (PV) resource in both narrowband and broadband wavelengths. This study conducts an evaluation of the spectral irradiances from the PV resource data set using surface-based observations at NREL's Solar Radiation Research Laboratory and the University of Oregon. The results demonstrate that the PV resource has a generally good agreement with the long-term observations in both clear-sky and cloudy-sky conditions. Further research is needed to reduce the overestimation of visible irradiances in clear-sky conditions and the underestimation of near-infrared irradiances in cloudy-sky conditions. 


\section{Table of Contents}

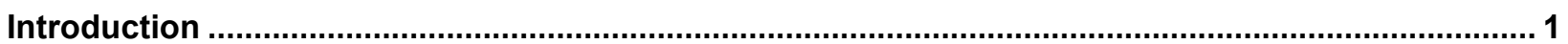

1 The PV Resource Data from the NSRDB........................................................................... 2

2 An Evaluation of the Spectral Irradiance Data Using Observations at NREL's SRRL and the

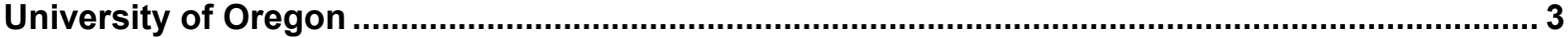

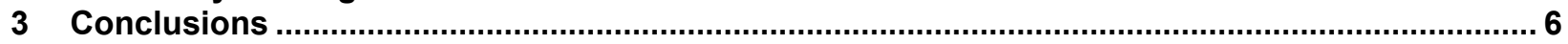

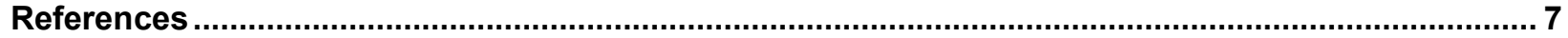




\section{List of Figures}

Figure 1. The pop-up window to order PV resource data from the NSRDB website ................................ 2

Figure 2. A comparison of spectral irradiances on (left) clear-sky and (right) cloudy-sky scenes at

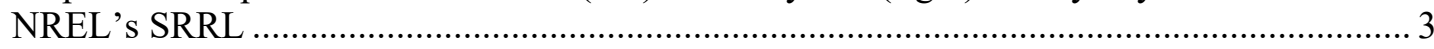

Figure 3. A comparison of spectral irradiances on (left) clear-sky and (right) cloudy-sky scenes at the

University of Oregon ........................................................................................... 4 3

Figure 4. A comparison of the long-term averaged spectral irradiances at NREL's SRRL and the

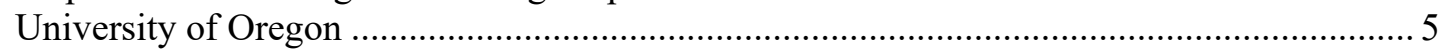

Figure 5. A comparison of the spectral irradiances at NREL's SRRL and the University of Oregon .......... 5 


\section{Introduction}

Models estimating the production from solar energy conversion systems often assume isotropic diffuse radiation in both the downwelling and upwelling directions (Badescu 2002; Liu and Jordan 1963; Xie, Sengupta, and Dooraghi 2018). Other conventional models compute plane-ofarray (POA) irradiances by empirically converting global horizonal irradiance and direct normal irradiance to irradiance over inclined surfaces (Perez et al. 1987). In view of the previous modeling efforts to compute POA irradiance and spectral irradiance, we observe several bottlenecks that cannot be easily avoided by the current framework: (1) The empirical equations, though efficiently used in the transposition models and spectral models to reduce the overall uncertainty in the training data, are unable to guarantee consistent accuracy in all specific scenarios because they neglect the underlying physics with complex combinations of aerosol, cloud, and land surface properties. (2) A transposition model needs to incorporate a spectral model to compute spectral irradiance in the POA even though the algorithms in these models are developed using different data sources. This can by itself lead to extra uncertainties compared to individual uncertainties when the models are used independently.

To address the drawbacks of the transposition models, spectral models, and radiative transfer models, Xie and Sengupta (2018) developed the Fast All-sky Radiation Model for Solar applications with Narrowband Irradiances on Tilted surfaces (FARMS-NIT) to solve the radiative transfer equation for the individual photon paths and thereby compute spectral irradiance in the POA (Xie and Sengupta 2018; Xie, Sengupta, and Wang 2019). The clear-sky atmospheric properties, e.g., the optical thickness of the atmosphere, are efficiently solved by the Simple Model of the Atmospheric Radiative Transfer of Sunshine (SMARTS) (Gueymard 1995) in 2002 wavelength bands from $0.28-4.0 \mu \mathrm{m}$. The clear-sky radiances are numerically obtained by computing the absorption, scattering, and reflection by aerosols with a single-scattering assumption. The cloudy-sky radiances are associated with the cloud transmittance precomputed by a 64-stream discrete ordinates radiative transfer (DISORT) model (Stamnes et al. 1998) and Rayleigh scattering above and under the cloud. The integration of the radiances over the inclined surfaces leads to spectral POA irradiances for any photovoltaic (PV) tilt directions. Following advanced studies on the atmospheric properties using satellite observations (Lawless, Xie, and Yang 2006; Minnis et al. 2020; Minnis et al. 2011; Xie 2010, 150; Xie and Liu 2013; Xie et al. 2014; Xie et al. 2020; Xie et al. 2019; Xie et al. 2012a; Xie et al. 2012b), FARMS-NIT has been implemented in the National Solar Radiation Database (NSRDB) (Habte et al. 2020; Sengupta et al. 2018; Xie, Sengupta, and Dudhia 2016) to provide the PV resource over Central and North America.

Although FARMS-NIT has been validated using surface-based observations at the National Renewable Energy Laboratory's (NREL's) Solar Radiation Research Laboratory (SRRL) (Xie and Sengupta 2018; Xie, Sengupta, and Dooraghi 2018; Xie et al. 2019), more comprehensive validation is needed in various scenes, surface orientations, tracking surfaces, and climate zones. In this study, the PV resource data disseminated by the NSRDB website are validated by longterm observations at NREL's SRRL and the University of Oregon. 


\section{The PV Resource Data from the NSRDB}

Figure 1 demonstrates the pop-up window on the NSRDB website to download the PV resource data. With the user's selection of location and PV orientation, FARMS-NIT and NSRDB data are used to compute the POA irradiance in real time. The cloud properties from the NSRDB are aggregated to 4-km and 30-minute resolutions. The spectral irradiance data are computed by FARMS-NIT for 2002 wavelengths from $280 \mathrm{~nm}$ to $4,000 \mathrm{~nm}$. The data are at $0.5-\mathrm{nm}$ intervals from $280 \mathrm{~nm}$ through $400 \mathrm{~nm}$ and at $1-\mathrm{nm}$ intervals from $400 \mathrm{~nm}$ through 1,700 nm. The intervals increase to $5 \mathrm{~nm}$ from $1,700 \mathrm{~nm}$ through $4,000 \mathrm{~nm}$.

The PV resource data for each round hour are available within 1-10 minutes after receiving the user's order. An email notification will be sent to users when the data are ready to download. More details on the PV resource data are available from the NSRDB website, https://nsrdb.nrel.gov. In this study, the spectral data from the PV resource are scaled to ensure consistency between the spatial integration of the spectral irradiances in the downwelling direction and the global horizontal irradiance data from the NSRDB.

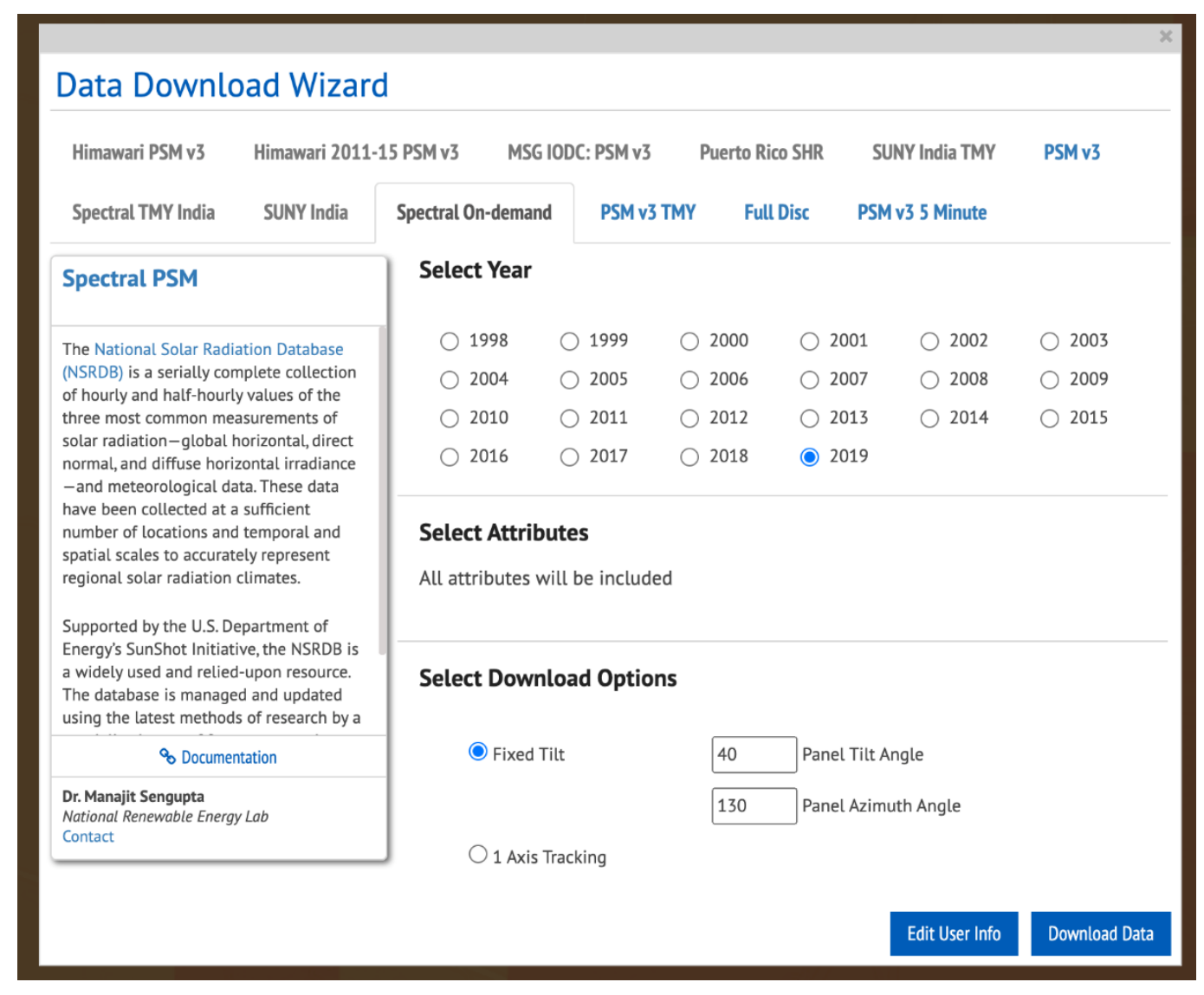

Figure 1. The pop-up window to order PV resource data from the NSRDB website 


\section{An Evaluation of the Spectral Irradiance Data Using Observations at NREL's SRRL and the University of Oregon}

In this study, the spectral irradiances from the PV resource data are evaluated using surfacebased observations at NREL's SRRL and the University of Oregon. For NREL's SRRL, the spectral irradiances are measured by a horizontal EKO WISER spectroradiometer system consisting of a set of instruments, such as MS-710 and MS-712. The spectral data from 1/1/2019 to $12 / 31 / 2019$ on the horizontal surface are given at $1-\mathrm{nm}$ intervals from $350 \mathrm{~nm}$ to $1,650 \mathrm{~nm}$. For the University of Oregon, the spectral data are measured by a MS-711 mounted on a 1-axis tracking system to cover 1-nm intervals from $300 \mathrm{~nm}$ to 1,100 nm. More than one year data from $8 / 23 / 2018$ to $12 / 31 / 2019$ are considered.
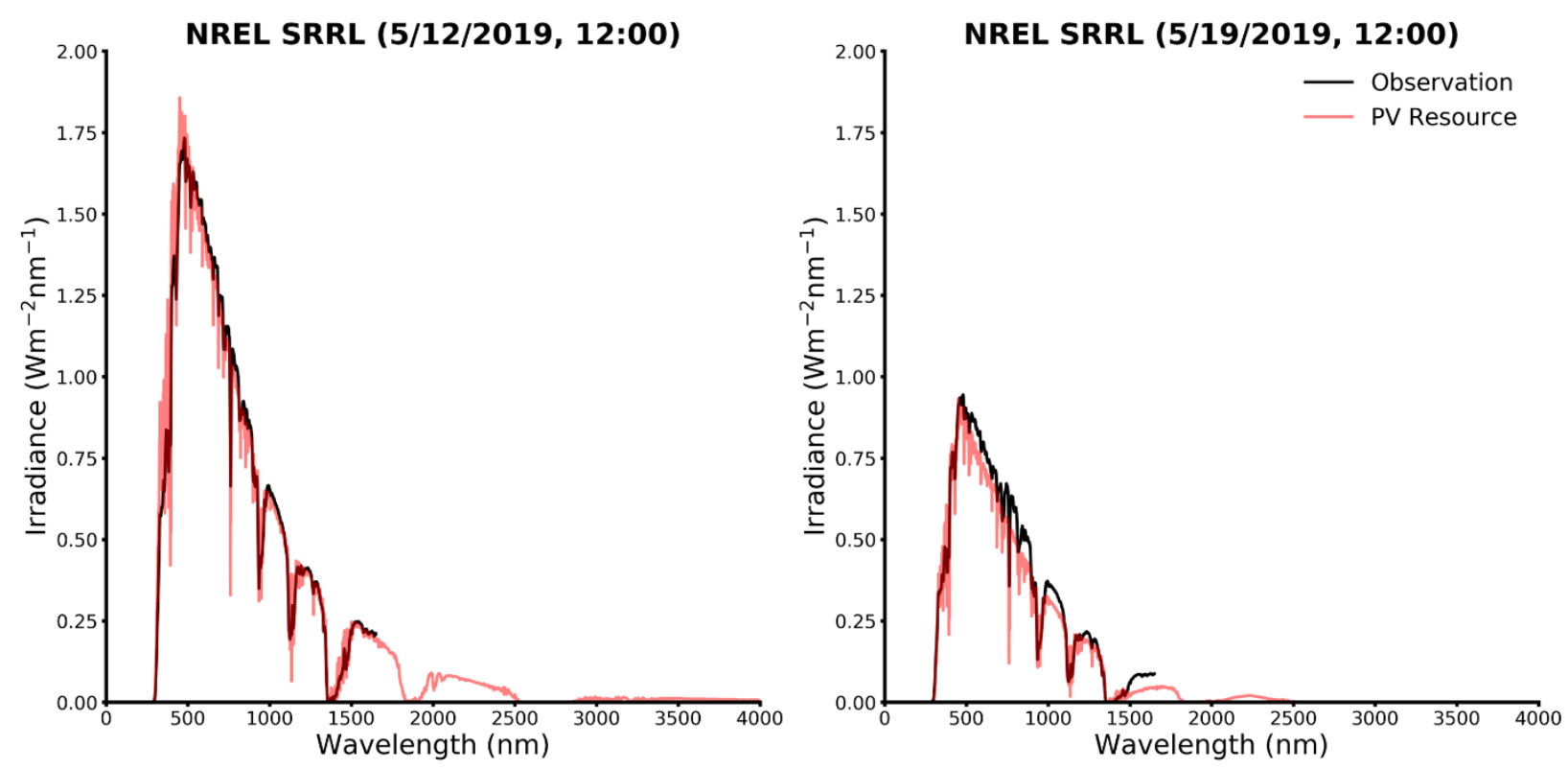

Figure 2. A comparison of spectral irradiances on (left) clear-sky and (right) cloudy-sky scenes at NREL's SRRL 

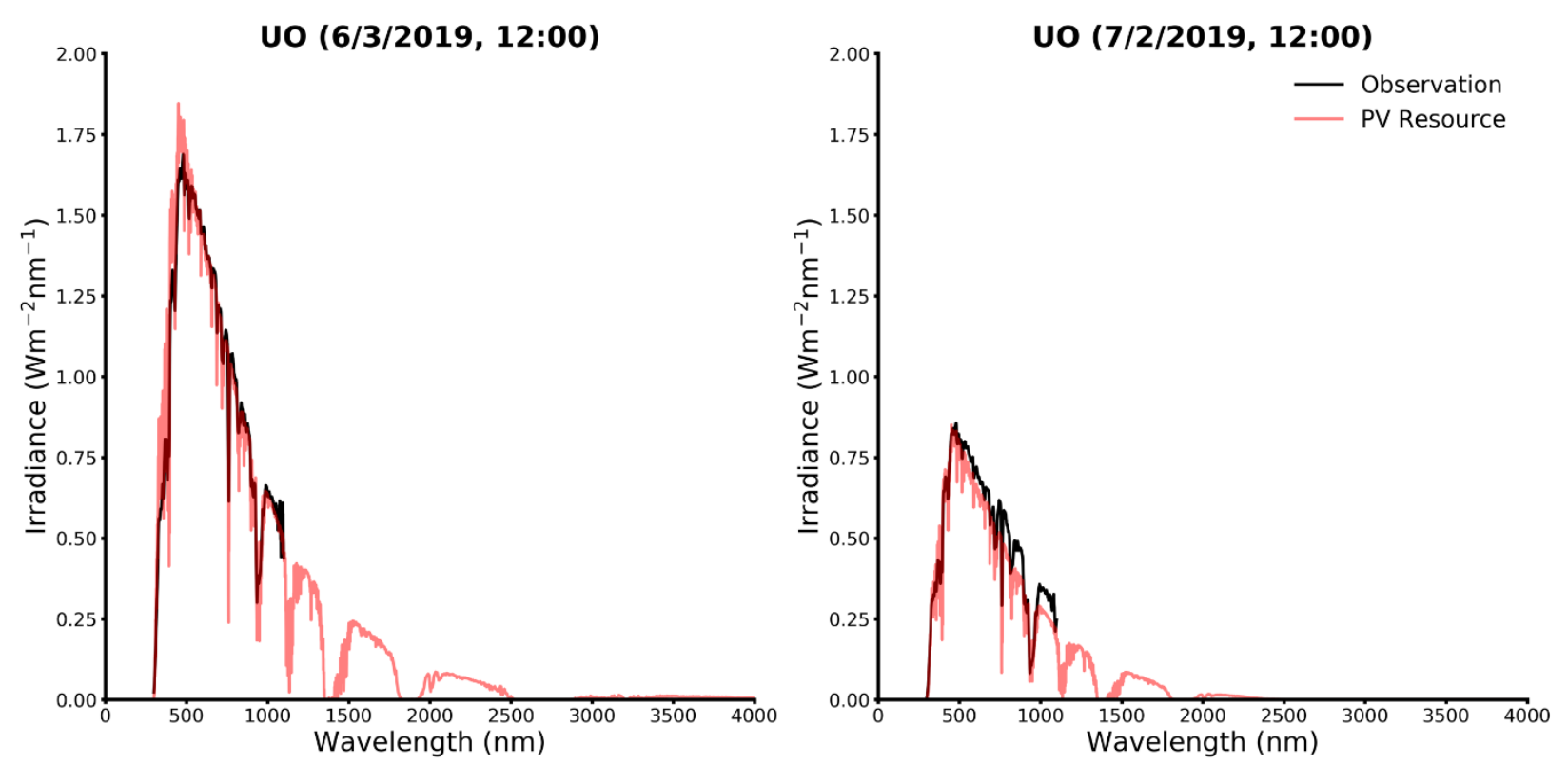

Figure 3. A comparison of spectral irradiances on (left) clear-sky and (right) cloudy-sky scenes at the University of Oregon

It is important to know that any data point is not exact, and there are uncertainties associated with the data. Even if the data match, there is still uncertainty in the data, and the match can only be as good as the data or the model. Still, it is always builds confidence in the model to have the modeled and measured data match even if there are systematic uncertainties and biases in the measured data. It is useful to look at clear-sky and cloudy-sky conditions over the year to see how well models and data match. Figures 2 and 3 illustrate the spectral irradiances at NREL's SRRL and the University of Oregon, respectively. The curve of the measured data is smoother than that of the modeled data because the measurements by the spectroradiometers are recorded at 1-nm separations. The spectral model data are recorded at smaller wavelength intervals. More importantly, the measured data at a given wavelength also include measurements from other nearby wavelengths because the spectroradiometer has an average full width at half maximum of less than $7 \mathrm{~nm}$. This has the effect of averaging over a range of wavelengths. If the full width at half maximum is a Gaussian distribution and is consistent over all wavelengths, the effect of this spread can be calculated. Without actual laboratory tests, however, it is difficult to address this issue in a comprehensive manner. The spectroradiometer also has a directional response that is better than 5\% for the MS-711. This can affect any comparison. On the one-axis tracker, the spectroradiometer is pointing more toward the sun and should have minimal directional affects; however, that must be proven. Figures 2 and 3 show that the clear-sky irradiances from the PV resource data are underestimated in the visible wavelengths, whereas a much better agreement can be found in the near-infrared wavelengths. This probably indicates an underestimation of the transmittance of the aerosol. For cloudy-sky conditions, however, the spectral irradiances from the PV resource data are underestimated. At specific wavelengths, e.g., $950 \mathrm{~nm}$, the modeled and measured data can be considerably different. This is caused by the spectral measurements having a full width at half maximum of $7 \mathrm{~nm}$ or less; therefore, the measurement at a given wavelength is a combination of measurements from the surrounding wavelengths as well as at the given wavelength. 
The disparity at specific wavelengths can be reduced in the long-term averaged spectral irradiances, as shown in Figure 4.
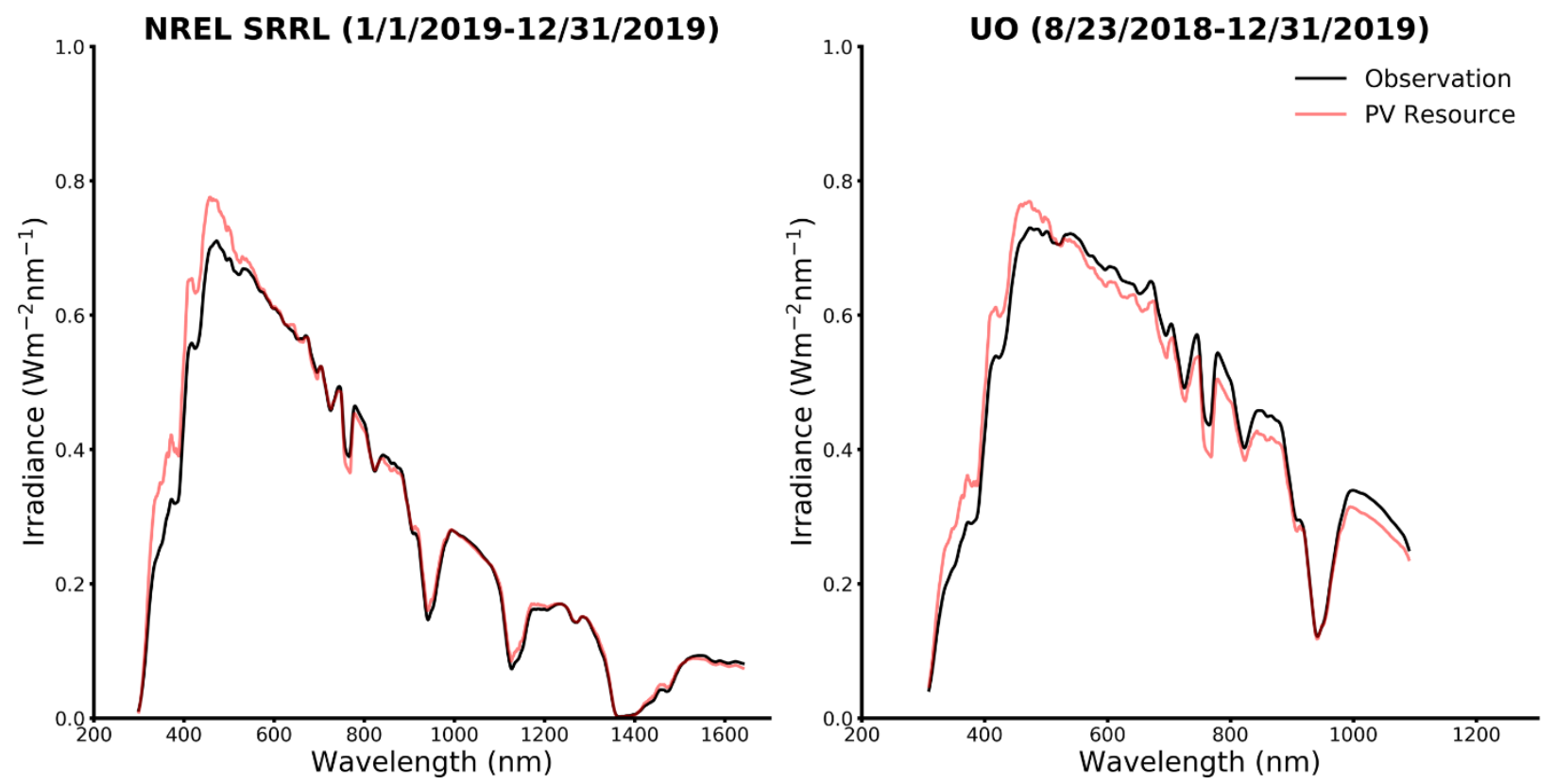

Figure 4. A comparison of the long-term averaged spectral irradiances at NREL's SRRL and the University of Oregon

Figure 5 compares the spectral irradiances from the PV resource data in all the wavelengths with surface observations. Because of the different wavelength intervals, data from the PV resource and surface observations are both averaged in 20-nm intervals. The model shows that the simulation and surface observation have a generally good agreement.
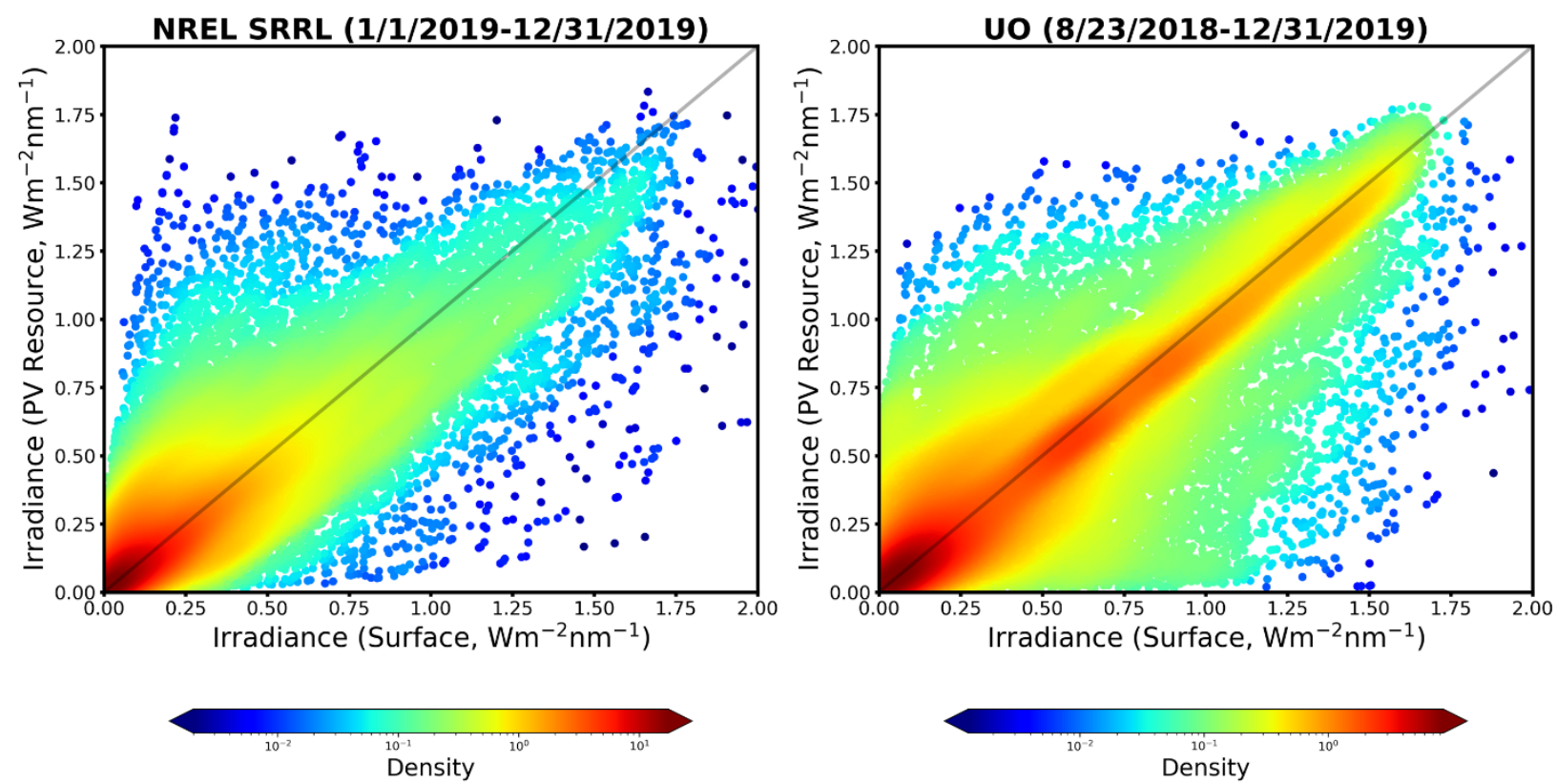

Figure 5. A comparison of the spectral irradiances at NREL's SRRL and the University of Oregon 


\section{Conclusions}

This study evaluates the spectral irradiance data from the PV resource product of the NSRDB. Approximately 1 year of surface observations at NREL's SRRL and the University of Oregon are compared with the spectral irradiances computed by FARMS-NIT and NSRDB data. The spectral irradiances received on a horizontal surface and a 1-axis tracking system at NREL's SRRL and the University of Oregon, respectively, are investigated.

It can be concluded that the PV resource data have a generally good agreement with the longterm observations; however, some differences are noticeable. The clear-sky irradiances at visible wavelengths are underestimated by the PV resource data. This is probably caused by the uncertainty in the aerosol optical depths at the wavelengths. On the other hand, the cloudy-sky irradiances at near-infrared wavelengths are slightly overestimated by the PV resource data. A larger difference between the PV resource data and surface observations can be seen at specific wavelengths that are particularly sensitive to water vapor absorption. This can be related to the relatively coarse wavelength resolution in the observations as well as the influence from the surrounding wavelengths. Moreover, some of the differences observed could also be attributed to the uncertainty of the spectroradiometers. 


\section{References}

Badescu, V. 2002. “3D Isotropic Approximation for Solar Diffuse Irradiance on Tilted Surfaces." Renewable Energy 26: 221-23.

Gueymard, C. 1995. SMARTS2: A Simple Model of the Atmospheric Radiative Transfer of Sunshine: Algorithms and Performance Assessment. Cocoa, FL: Florida Solar Energy Center Cocoa.

Habte, A., M. Sengupta, C. Gueymard, A. Golnas, and Y. Xie. 2020. "Long-Term Spatial and Temporal Solar Resource Variability Over America Using the NSRDB Version 3 (1998-2017)." Renewable and Sustainable Energy Reviews 134: 110285.

Lawless, R., Y. Xie, and P. Yang. 2006. "Polarization and Effective Mueller Matrix for Multiple Scattering of Light by Nonspherical Ice Crystals.” Optics Express 14 (14): 6381-93.

Liu, B., and R. Jordan. 1963. "The Long-Term Average Performance of Flat-Plate Solar-Energy Collectors.” Solar Energy 7 (2): 53-74.

Minnis, P., S. Sun-Mack, D. Young, P. W. Heck, D. P. Garber, Y. Chen, D. A. Spangenberg, R. F. Arduini, Q. Z. Trepte, W. L. Smith, J. K. Ayers, S. C. Gibson, W. F. Miller, G. Hong, V. Chakrapani, Y. Takano, K. N. Liou, Y. Xie, and P. Yang. 2011. "CERES Edition 2 Cloud Property Retrievals Using TRMM VIRS and TERRA and AQUA MODIS Data, Part I: Algorithms." IEEE Transactions on Geoscience and Remote Sensing 49 (11): 4374-4400.

Minnis, P., S. Sun-Mack, Y. Chen, F. Chang, C. Yost, W. L. Smith, P. W. Heck, R. F. Arduini, S. Bedka, Y. Yi, G. Hong, Z. Jin, D. Painemal, R. Palikonda, B. Scarino, D. A. Spangenberg, R. Smith, Q. Z. Trepte, P. Yang, and Y. Xie. 2020. "CERES MODIS Cloud Product Retrievals for Edition 4. Part I: Algorithm Changes." IEEE Transactions on Geoscience and Remote Sensing: $1-37$.

Perez, R., R. Seals, P. Ineichen, R. Stewart, and D. Menicucci. 1987. “A New Simplified Version of the Perez Diffuse Irradiance Model for Tilted Surfaces.” Solar Energy 39 (3): 221-31.

Sengupta, M., Y. Xie, A. Lopez, A. Habte, G. Maclaurin, and J. Shelby. 2018. "The National Solar Radiation Database (NSRDB)." Renewable and Sustainable Energy Reviews 89: 51-60.

Stamnes, K., S. C. Tsay, W. Wiscombe, and K. Jayaweera. 1988. "Numerically Stable Algorithm for Discrete-Ordinate-Method Radiative Transfer in Multiple Scattering and Emitting Layered Media." Applied Optics 27 (12): 2502-09.

Xie, Y. 2010. "Study of Ice Cloud Properties from Synergetic Use of Satellite Observations and Modeling Capabilities.” Ph.D. diss., Department of Atmospheric Sciences, Texas A\&M University.

Xie, Y., and M. Sengupta. 2018. “A Fast All-Sky Radiation Model for Solar Applications with Narrowband Irradiances on Tilted Surfaces (FARMS-NIT): Part I. The Clear-Sky Model.” Solar Energy 174: 691-702. 
Xie, Y., and Y. G. Liu. 2013. "A New Approach for Simultaneously Retrieving Cloud Albedo and Cloud Fraction from Surface-Based Shortwave Radiation Measurements." Environmental Research Letters 8. doi:10.1088/1748-9326/1088/1084/044023.

Xie, Y., M. Sengupta, and C. Wang. 2019. “A Fast All-Sky Radiation Model for Solar Applications with Narrowband Irradiances on Tilted Surfaces (FARMS-NIT): Part II. The Cloudy-Sky Model. Solar Energy 188: 799-812.

Xie, Y., M. Sengupta, and J. Dudhia. 2016. "A Fast All-Sky Radiation Model for Solar applications (FARMS): Algorithm and Performance Evaluation.” Solar Energy 135: 435-45.

Xie, Y., M. Sengupta, and M. Dooraghi. 2018. "Assessment of Uncertainty in the Numerical Simulation of Solar Irradiance Over Inclined PV Panels: New Algorithms Using Measurements and Modeling Tools.” Solar Energy 165: 55-64.

Xie, Y., M. Sengupta, Y. Liu, H. Long, Q. Min, W. Liu, and A. Habte. 2020. "A Physics-Based DNI Model Assessing All-Sky Circumsolar Radiation.” iScience 22. doi.org/10.1016/j.isci.2020.100893.

Xie, Y., P. Yang, G. W. Kattawar, P. Minnis, and Y. X. Hu. 2009. "Effect of the Inhomogeneity of Ice Crystals on Retrieving Ice Cloud Optical Thickness and Effective Particle Size." Journal of Geophysical Research 114: D11203. doi:11210.11029/12008JD011216.

Xie, Y., P. Yang, G. W. Kattawar, P. Minnis, Y. X. Hu, and D. Wu. 2012a. "Determination of Ice Cloud Models Using MODIS and MISR Data." International Journal of Remote Sensing 33: 4219-53.

Xie, Y., P. Yang, K. N. Liou, P. Minnis, and D. P. Duda. 2012b. "Parameterization of Contrail Radiative Properties for Climate Studies.” Geophysical Research Letters 39: L00F02. doi:10.1029/2012GL054043.

Xie, Y., Y. G. Liu, C. N. Long, and Q. L. Min. 2014. "Retrievals of Cloud Fraction and Cloud Albedo from Surface-Based Shortwave Radiation Measurements: A Comparison of 16-Year Measurements." Journal of Geophysical Research: Atmospheres 119 (14): 8925-40. 